\title{
(2) OPEN ACCESS \\ Digital marketplace to improve healthcare access and transparency in Vietnam
}

\author{
Beth Ann Lopez, ${ }^{1}$ Minh Le Viet, ${ }^{1}$ An Pham Le ${ }^{2}$
}

- Supplemental material is published online only. To view please visit the journal online (http://dx.doi.org/10.1136/ bmjinnov-2021-000694).

${ }^{1}$ Docosan Inc, Ho Chi Minh City, Viet Nam

${ }^{2}$ Grant and Innovation Center Ho Chi Minh City University of Medicine and Pharmacy, Ho Chi Minh City, Viet Nam

\section{Correspondence to}

Beth Ann Lopez, Docosan Inc., Ho Chi Minh City 70000, Viet Nam; lopez@docosan.com

Received 29 January 2021 Revised 15 March 2021 Accepted 21 March 2021 Published Online First

\section{Check for updates}

(c) Author(s) (or their employer(s)) 2021. Re-use permitted under CC BY-NC. No commercial re-use. See rights and permissions. Published by BMJ.

To cite: Lopez BA, Le Viet M, Pham Le A. BMJ Innov 2021;7:s1-s3.

\section{INTRODUCTION}

Vietnam's private medical sector is thriving, with per capita health spending doubling over the last decade. ${ }^{12}$ Since the government legalised private healthcare services in 1989 as part of wide-ranging Doi Moi reforms, the sector has experienced 'dramatic' expansion with 35000 clinics and 240 hospitals, up from only one private hospital in $1996 .^{3}$ While a large majority of Vietnam's more than 280000 hospital beds are public, ${ }^{4}$ private healthcare now accounts for $32.2 \%$ of total outpatient services and $6.3 \%$ of inpatient services, and is growing fast, with about 1300 new private clinics and 10 new private hospitals opening every year. ${ }^{5}$

While the outlook for the private healthcare market is positive, the presence of tens of thousands of small private clinics and hospitals across the country mean that fragmentation is an underlying issue. Quickly comparing a multitude of doctors based on basic criteria like price, quality, specialty and location is difficult. ${ }^{6}$ Booking an appointment can be even harder, leading many patients to skip this step altogether and gather in crowded waiting rooms. For doctors, finding new clients online is a sometimes confusing and expensive experience (online supplemental material 1). Meanwhile, stigma against accessing mental and sexual health services remains common. ${ }^{78}$

This manuscript describes an online healthcare marketplace, Docosan (www. docosan.com).

Docosan is a technology startup founded in early 2020 and headquartered in Ho Chi Minh City. Docosan's name is a combination of the English word 'doctor' and the Vietnamese term 'có sẵn', that is, 'available'.
Summary box

What are the new findings?

- Patients in Vietnam are more likely to report satisfaction with healthcare services if given a simple digital platform to find, book and compare options.

- Healthcare providers that struggle to find new clients benefit from an open platform specifically for connecting patients to professionals.

How might it impact on healthcare in the future?

- Digital marketplaces can help people access healthcare far more conveniently thanks to widespread smartphone penetration, similarly to how ridehailing startups transformed access to transportation.

- Such digital solutions may help healthcare providers better use digital technology to expand their client base beyond word-ofmouth circles.

Docosan allows patients to compare healthcare providers across 29 medical specialties, view pricing information, read real reviews of doctors, book appointments with providers online 24/7 and chat with primary care assistants. The platform is used by providers to manage bookings, offer promotions and send compliant health education and treatment reminder messages to patients. It features separate mobile applications for patients and providers as well as a website.

\section{METHODS}

To discover unmet needs, Docosan's founders surveyed 394 Vietnamese patients between July and August 2019, finding that Vietnamese patients struggle to navigate healthcare networks, with long wait times a bad enough problem 
that $10 \%$ of patients report having given up and gone home for their last healthcare appointment while only $16 \%$ of patients booked their last appointment in advance. Dissatisfaction was common, with 31\% rating their last appointment satisfaction as 'low' or 'very low'. The survey further found that provider decisions are tightly linked to family recommendations with $74 \%$ of patients reporting that healthcare decisions are made by the mother in their family unit. Other academic literature confirms the difficulty Vietnamese patients have in finding the right provider, with one study of 1459 patients in Hanoi finding that 'spending more time and cost does not improve' the likelihood of choosing a good healthcare provider due to 'problems with the quality of information and/or the efficiency of information'?

Based on these findings, Docosan built a customised software platform for patients to compare and book appointments with doctors and for doctors to reach new patient groups. Thanks to Vietnam's status as a local hub for tech talent, ${ }^{10}$ Docosan built a tech team relatively easily and beta launched in April 2020. The platform now consists of a patient-facing website and smartphone application along with a separate portal for doctors to manage bookings.

To build a network of doctors, Docosan employees visited clinics in person while also signing partnerships with private hospitals. To attract patients, Docosan chiefly used social media advertising. To vet doctors, Docosan collects notarised clinical licensing documents at both the clinic and provider level for each doctor on the network. To further address concerns around doctor quality, the Docosan platform offers a five-star rating system.

Docosan's terms and conditions make it clear that patient ratings are to remain impartial and cannot be influenced (by payment or other means) by healthcare providers-since most clinics well understand patients' fears about quality and want to assuage them, this is not a significant stumbling block in terms of expanding Docosan's provider base.

\section{RESULTS}

Launched in just April 2020, Docosan's network now has over 300 verified doctors providing more than 5300 different healthcare procedures with explicit prices, chiefly in Ho Chi Minh City and Hanoi.

In terms of patient satisfaction, the average patient reported experience rating across all doctors on the Docosan network is 4.83 stars out of five with their Docosan-booked healthcare professional. With the caveat that this data remains limited due to a smaller sample size of patients who left reviews on the site $(225$ patients), the percentage remains significantly higher than other surveys of Vietnamese healthcare satisfaction rates of $42 \% .{ }^{11}$ Additionally, $27 \%$ of patients have booked more than one appointment through the platform, the same repeat purchase rate considered favourable among e-commerce platforms ${ }^{12}$-let alone in the healthcare industry in which patients may only need care one or two times per year.

The average years of clinical experience of each doctor on the platform is 18 years, reflecting the company's strategy of targeting and onboarding experienced physicians at launch. Although most Docosan doctors practice in the private sector, Vietnam's large public healthcare field has also shown interest, with the dermatology department of Vietnam's largest public traditional medicine hospital signing up in December 2020 to be part of the Docosan network.

Docosan's top rated and booked practitioner is a female gynaecologist with decades of experience in the field while its second most popular member is a psychologist. As shown by early Docosan user interviews, because booking online is easier and more private, specialties like mental and sexual health benefit the most. Indeed, 34\% of Docosan's total bookings have been concentrated in these two fields.

\section{DISCUSSION}

Higher patient satisfaction rates show that using smartphones to provide a convenient way to approach medical treatment could encourage patients to shift from 'go to pharmacy and cure themselves' to 'go to clinic to have proper treatment', creating more demand for treatment that they may otherwise ignore. ${ }^{13}$ Docosan's growing doctor network shows providers are also interested in new ways of reaching patients which help bypass the healthcare marketplace's inefficiencies and fragmentation issues.

While Docosan is meant for all healthcare professionals, Docosan was able to successfully target mental health and obstetrics and gynaecology practitioners as early adopters in order to attract more patients to the platform. Docosan has succeeded at getting traction among smartphone-savvy, urban millennials. However, a key challenge is getting people outside this group to join as well. About $60 \%$ of Vietnam's population is rural $^{14}$ and $68 \%$ of rural people have a smartphone compared with $84 \%$ in urban areas. ${ }^{15}$ While the Vietnamese government has plans to increase smartphone penetration to $100 \%$ across the country by $2025,{ }^{16}$ this disparity makes underserved populations with a smartphone app will be more difficult. Docosan addresses this issue by allowing users to book appointments on behalf of others, so that, for example, a family member who does own a smartphone can access the app and book an appointment for a relative.

Vietnam's healthcare sector suffers from problems similar to many other emerging markets: uncertain doctor quality, difficulties with both finding the right doctor and booking an appointment, and stigma around certain specialties. Given these promising early results, we believe Docosan's platform model has strong potential to improve healthcare access and satisfaction for patients not only in Vietnam but also 
regionally. Doctor booking startups have now raised hundreds of millions of dollars from investors globally but the majority of this funding focuses on developed countries. ${ }^{17}$ However, emerging markets with high smartphone penetration offer strong potential for transformation in the way that people access and experience healthcare.

Twitter Beth Ann Lopez@docosanhealth

Contributors All authors contributed to the delivery of this collaborative project. BAL wrote the first draft of the manuscript, which was later edited by all authors.

Funding The authors have not declared a specific grant for this research from any funding agency in the public, commercial or not-for-profit sectors.

Competing interests None declared.

Patient consent for publication Not required.

Provenance and peer review Not commissioned; externally peer reviewed.

Supplemental material This content has been supplied by the author(s). It has not been vetted by BMJ Publishing Group Limited $(\mathrm{BMJ})$ and may not have been peer-reviewed. Any opinions or recommendations discussed are solely those of the author(s) and are not endorsed by BMJ. BMJ disclaims all liability and responsibility arising from any reliance placed on the content. Where the content includes any translated material, BMJ does not warrant the accuracy and reliability of the translations (including but not limited to local regulations, clinical guidelines, terminology, drug names and drug dosages), and is not responsible for any error and/or omissions arising from translation and adaptation or otherwise.

Open access This is an open access article distributed in accordance with the Creative Commons Attribution Non Commercial (CC BYNC 4.0) license, which permits others to distribute, remix, adapt, build upon this work non-commercially, and license their derivative works on different terms, provided the original work is properly cited, appropriate credit is given, any changes made indicated, and the use is non-commercial. See: http://creativecommons.org/ licenses/by-nc/4.0/.

\section{REFERENCES}

1 World Health Organization. Human resources for health country profiles: Viet Nam, 2016. Available: https://iris.wpro. who.int/handle/10665.1/13476 [Accessed 28 Jan 2021].

2 World Bank. Current health expenditure per capita Vietnam. Available: https://data.worldbank.org/indicator/SH.XPD. CHEX.PC.CD?locations $=\mathrm{VN}$ [Accessed 28 Jan 2021].

3 SM L, Govindaraj R, Bradencamp C. Public-private partnerships for health in Vietnam. world bank. Available: https://openknowledge.worldbank.org/bitstream/handle/10986/ 33724/9781464815744.pdf[Accessed 12 Mar 2021].

4 World Health Organization. Human resources for health country profiles - Vietnam. available. Available: https:// www.google.com $/$ url sa $=t \& r c t=j \& q=\&$ esrc $=s \&$ source $=$ web\&cd $=\& v e d=2$ ahUKEwj-h774n6rvAhV6yosBHY-
dDtEQFjAAegQICRAD\&url=https\%3A\%2F\%2Fapps.who. int $\% 2$ Firis $\% 2$ Frest $\% 2$ Fbitstreams $\% 2 F 1247490 \% 2$ Fretrieve\& usg=AOvVaw0sbuI67ZErVvWKOtSIERxC [Accessed 12 Mar 2021].

5 Govindaraj R, Bradencamp C. Public-private partnerships for health in Vietnam. world bank. Available: https:// openknowledge.worldbank.org/bitstream/handle/10986/33724/ 9781464815744.pdf [Accessed 12 Mar 2021].

6 Vuong QH. Be rich or don't be sick: estimating Vietnamese patients' risk of falling into destitution. Springerplus 2015;4:529.

7 Do M, McCleary J, Nguyen D, et al. Mental illness public stigma and generational differences among Vietnamese Americans. Community Ment Health J 2020;56:839-53.

8 Van Minh H, Ha BTT, Chuong NC, Minh HV, et al. Women's health and health care in Vietnam. Health Care Women Int 2018;39:4:364-7.

9 Vuong Q-H, Nguyen T-K. Vietnamese patients' choice of healthcare provider: in search of quality information, 2015. Available: https://www.researchgate.net/publication/ 305650300_Vietnamese_patients'_choice_of_healthcare_ provider_in_search_of_quality_information

10 YCP Solidance. A look forward: How digitalization is transforming Vietnam's healthcare system, 2020.

11 Nguyen T, Nguyen H, Dang A. Determinants of patient satisfaction: lessons from large-scale inpatient interviews in Vietnam. PLoS One 2020;15:e0239306.

12 Yin S. Take the "selling" out of "upselling": how to upsell to customers and improve the shopping experience. Available: https://www.shopify.com/blog/upselling-and-cross-selling? fbclid=IwAR1FjXU_-CwbmvMgL_Z6SOj4ic-LNkmDxZsEarj09S_S5c01-4t0V9_F-U [Accessed 28 Jan 2021].

13 Huong NT, Vree M, Duong BD, et al. Delays in the diagnosis and treatment of tuberculosis patients in Vietnam: a crosssectional study. BMC Public Health 2007;7:110.

14 An K, Doan T. Over 39\% of Vietnam population lives in cities. Hanoi Times. Available: http://hanoitimes.vn/over39-of-vietnam-population-lives-in-urban-areas-313299.html [Accessed 10 Feb 2021].

15 Nielsen. Smartphone keeps up the growth momentum with increasing usage incidences in key cities; whilst rural smartphone users reaching up to $68 \%$. Available: https://www. nielsen.com/wp-content/uploads/sites/3/2019/04/Web_Nielsen_ Smartphones20Insights_EN.pdf [Accessed 10 Feb 2021].

16 Son M. 4 giải pháp để phổ cập điện thoại thông Minh V O 2025. Ministry of information and communications website. Available: https://mic.gov.vn/mic_2020/Pages/TinTuc/145314/ 4-giai-phap-de-pho-cap-dien-thoai-thong-minh-vao-2025.html [Accessed 2 Feb 2021].

17 MedicalStartups.org. Top 24 doctor booking startups. Available: https://www.medicalstartups.org/top/doctor-booking/ [Accessed 28 Jan 2021]. 